\title{
Visuo-postural dependency index (VPDI) in human postural control
}

\author{
Alessander Danna-dos-Santos ${ }^{1 *}$ (D, Maria M. Ribeiro dos Santos ${ }^{2}$, Alessandra T. Magalhães ${ }^{3}$, Vinicius S. Cardoso ${ }^{3}$,
} Patricia Driusso ${ }^{4}$, Luis Mochizuki ${ }^{5}$ and Adriana M. Degani ${ }^{1}$

\begin{abstract}
Background: Computerized stabilometry has been utilized to investigate the effect of vision on the neuromechanisms of human postural control. However, this approach lacks operational methods to quantify visual dependency during upright stance. This study had three goals: (1) To introduce the concept of visuo-postural dependency indices (VPDI) representing balance sway characteristics in multiple analytical domains (spatial, temporal, frequency, and structural), (2) To investigate the age and gender effects on VPD/s, and (3) To investigate the degree of relationships between VPDI and both subjective visual vertical and horizontal perception (SW and SVH, respectively).

Methods: 102 participants (16 to 80 years old) performed bipedal stances on a force platform with eyes open and closed. Response variables included the VPDIs computed for each postural index. In addition, 29 participants also performed SW and SVH assessments.

Results: Fifteen VPD/s showed to be robust indicators of visual input modulation, and the variation across their magnitudes of modulation revealed a non-homogeneous response to changes in visual stimuli. Gender and age were not found to be a significant factor to VPDI modulation.
\end{abstract}

Conclusions: VPD/s revealed to be potential measures capable to quantitatively assess visuo-postural dependency and aid the assessment of fall risks and balance impairments.

Keywords: Visual perception, Visual dependency, Postural control, Aging

\section{Background}

Body spatial orientation depends directly on a precise and continuous integration of visual, vestibular, and somatosensory inputs. The integration of these inputs supports the central nervous system (CNS) to create a time-to-time neural representation of the body configuration, and its relation with the surrounding environment $[1,2]$. The accuracy of this internal representation is essential for the implementation of successful corrective adjustments to internal and external mechanical forces

\footnotetext{
* Correspondence: alessander.santos@wmich.edu

'Laboratory for Advances in Rehabilitation Sciences, Department of Physical Therapy, Western Michigan University, 1903 W Michigan Av., Office \# 3454, Kalamazoo, MI 49008-5383, USA

Full list of author information is available at the end of the article
}

applied to the axial skeleton. The visual system, for example, uses fine oculomotor movements (such as smooth pursuit and saccadic movements) along with peripheral visual perception to provide a reference for the body's verticality, head/body orientation, and body's relative velocity to the visual world [3-5].

The relative importance of visual inputs on postural control is commonly referred to as visual dependency, and its applications in both laboratory and clinical settings have grown in importance. This importance is rooted to its potential role on improving predictive models of higher risks of falling in adults. Historically, the term visual dependency was coined based on Witkin and Asch (1948), who introduced the analog rod-and-

(c) The Author(s). 2021 Open Access This article is licensed under a Creative Commons Attribution 4.0 International License, which permits use, sharing, adaptation, distribution and reproduction in any medium or format, as long as you give appropriate credit to the original author(s) and the source, provide a link to the Creative Commons licence, and indicate if changes were made. The images or other third party material in this article are included in the article's Creative Commons licence, unless indicated otherwise in a credit line to the material. If material is not included in the article's Creative Commons licence and your intended use is not permitted by statutory regulation or exceeds the permitted use, you will need to obtain permission directly from the copyright holder. To view a copy of this licence, visit http://creativecommons.org/licenses/by/4.0/ The Creative Commons Public Domain Dedication waiver (http://creativecommons.org/publicdomain/zero/1.0/) applies to the data made available in this article, unless otherwise stated in a credit line to the data. 
frame test as a subjective visual procedure to estimate one's degree of reliance on visual information for spatial orientation [6]. An important find was the larger levels of perceptual errors in a percentage of the healthy persons studied. These results suggest that part of our healthy population is naturally prone to higher risks of falling when their vision is impaired and/or obstructed. Although this higher risk of falling may be subclinical at younger ages, they are likely amplified by aging and/or neurological conditions. Based on this rationale, indices quantifying degrees of visual dependency could be used as an early indicator for increased fall risk. However, testing this rationale depends on the development and investigation of a multi-dimensional panel of indices representing multiple characteristics of human bipedal vertical control.

Along the past decades, the analog rod-and-frame test has been replaced by computerized methods with improved accuracy. For example, individuals are asked to adjust a projected laser bar, so the bar is perceived as either in its most vertical or horizontal position. The angular error between the bar placement and the true vertical or horizontal is computed (subjective visual vertical, $S V V$, and subjective visual horizontal, $S V H$, respectively). This valid otoneurologic clinical test has been successfully used to investigate the integrity of visual and vestibular otolithic information in different health conditions [7-9]. Despite improved accuracy and easy application, $S V V$ and $S V H$ tests have been limited to cases of severe impairments, such as vestibular neuritis, cerebellopontine angle tumor, posterior canal benign paroxysmal positional vertigo, and other peripheral and central vestibular lesions [10-17]. This limitation has hindered its utilization in mild and moderate cases. Therefore, less severe visual and vestibular impairments may go undetected and untreated.

Considering ample evidence suggesting human postural control as a complex series of neurophysiological processes involving several cortical and subcortical structures [18], the univariate nature of $S V V / S V H$ testing outcomes seems to restrict its sensitivity. A potential method to improve $S V V$ and $S V H$ outcomes is the analysis of the body's sway behavior (computerized stabilometry). This assessment is based on the recording of the body's centre of pressure (COP) coordinates on a force platform during the execution of quiet bipedal vertical stance $[19,20]$. Once recorded, these signals are submitted to computational procedures for the extraction of multiple indices corresponding to characteristics belonging to multiple analytical domains, i.e., spatial, temporal, frequency, and structural domains [21, 22]. In fact, this principle has been utilized to investigate the effect of vision on postural control by analyzing body sway behavior during quiet stance with eyes open and closed
[23-27]. Despite their importance, these investigations were not designed to establish an actual index representing the visual dependency during postural control, nor its potential modulation across the lifespan. Such gap in the scientific literature remains.

A plausible solution to overcome this gap is the development of postural indices dedicated to the quantification of visual dependency. For example, the computation of ratios between indices obtained from different conditions of visual inputs availability could be a potential marker for visual dependency. Under this approach, individuals showing larger visual dependency would likely develop ratios departing from the normative. The use of postural index ratios was introduced by Nashner and Peters (1990) as a concept for the sensory organization testing where major sensory modalities are manipulated for the establishment of ratio-based scores [28]. This method has been clinically used in the past decades. However, the ratios and scores (i.e. maximum amplitudes of body sway and COP's shortest distances to the base of support's boundary) still represent only a fraction of all indices reported in laboratory as sensitive to modulation of visual inputs [28-30].

The present study was designed to bridge this gap. Here, we introduced the use of a set of Visuo-Postural Dependency Index (VPDI) representing the normalized differences calculated for multiple variables of interest recorded via computerized stabilometry, and under different conditions of visual inputs availability. We investigated the modulation of each VPDI to establish their ability to capture the effects of changes in visual inputs, their potential modulation across the lifespan, their correlations to $S V V$ and $S V H$ testing results, and a potential gender effect. Our main hypothesis is centered on the expectancy that VPDIs representing multiple analytical domains would be sensitive to the modulation of visual inputs. We also hypothesized that visual dependency would decrease with age. This study represents a logical progression on the study of visuo-postural dependency by providing a comprehensive panel of postural behavioral quantities and establishing an initial set of normative data across the adult life span. Moreover, the present study will offer an initial analysis of the potential relationship between $S V V / S V H$ testing and stabilometric indices.

\section{Methods \\ Participants}

102 participants, aging 16 to 80 years old, participated in this study (75 females; mean height 166.4 (SD $11.4 \mathrm{~cm}$ ), mean weight 64.7 (SD $12.6 \mathrm{~kg}$ ). This study was performed in accordance with the Declaration of Helsinki and approved by the Institutional Review Board of the University of Montana (Missoula, MT. USA). 
Procedures, associated risks, and potential benefits of participation were explained to each participant and written informed consent was obtained prior to commencement of the study. Exclusion criteria for participation included history of falls within past six months, history of head trauma, traumatic brain injury, cerebral vascular accident, seizure disorders, substance abuse (drugs, alcohol, or controlled medication), peripheral neuropathy, acute upper or lower extremity injury, metallic implants in spine or extremities, neurosurgery, and abnormalities of cranial nerve functions.

\section{Apparatus}

\section{Quiet stance (VPDI) recording}

A force platform (AMTI BP400600, AMTI Inc., USA) was used to acquire components of the ground reaction force (GRF) and moments of force around the frontal and sagittal axes. These signals were used to compute the body's center of pressure (COP) coordinates in anterior-posterior and medial-lateral directions (COPap and COPml, respectively) as:

$$
\begin{aligned}
& C O P_{a p}=\frac{-h F_{x}-M_{y}}{F_{z}} \\
& C O P_{m l}=\frac{-h F_{y}-M_{x}}{F_{z}}
\end{aligned}
$$

where $h$ is the height of the base of support above the force plate, $F_{x}$ is the anterior-posterior component of the GRF, $F_{y}$ is the medial-lateral component of the GRF, $F_{z}$ is the vertical component of the GRF, $M_{x}$ is the moment of force around the sagittal axis, and $M_{y}$ is the moment of force around the frontal axis. All signals were sampled at $100 \mathrm{~Hz}$ with 12-bit resolution.

\section{SVV and SVH perception recording}

An I-Portal system (Neurokinetics, USA) was used to assess participant's $S V V$ and $S V H$ perception. Static $S V V$ and $S V H$ are valid otoneurologic tests to assess the perception of gravitational vertical and horizontal respectively [31]. Absolute limit $S V V$ and $S V H$ deviation in healthy individuals is around $2.0^{\circ}$ to $2.5^{\circ}$. These values are considered reliable for both research and clinical use [32-36].

\section{Experimental procedure}

\section{Quiet stance (VPDI) recording}

For the quiet stance recordings, all participants were barefoot and asked to stand quiet for $120 \mathrm{~s}$ on the top of the force plate with eyes either open (BEO - bipedal eyes open, Fig. 1a) or closed (BEC - bipedal eyes closed). Feet were placed in parallel and $15 \mathrm{~cm}$ apart. Consistency of foot placement across participants was achieved by markings on the surface of the force plate. Participants were instructed to cross their arms against their chest while remaining as vertical as possible. During BEO condition, participants focused their vision on a physical static point placed at eyes level and $1.5 \mathrm{~m}$ away. During BEC condition, participants kept their eyes fully closed. To avoid any transient effects during the initial moments of a trial, data recording was initiated five seconds after the initial position was adopted by the participant.

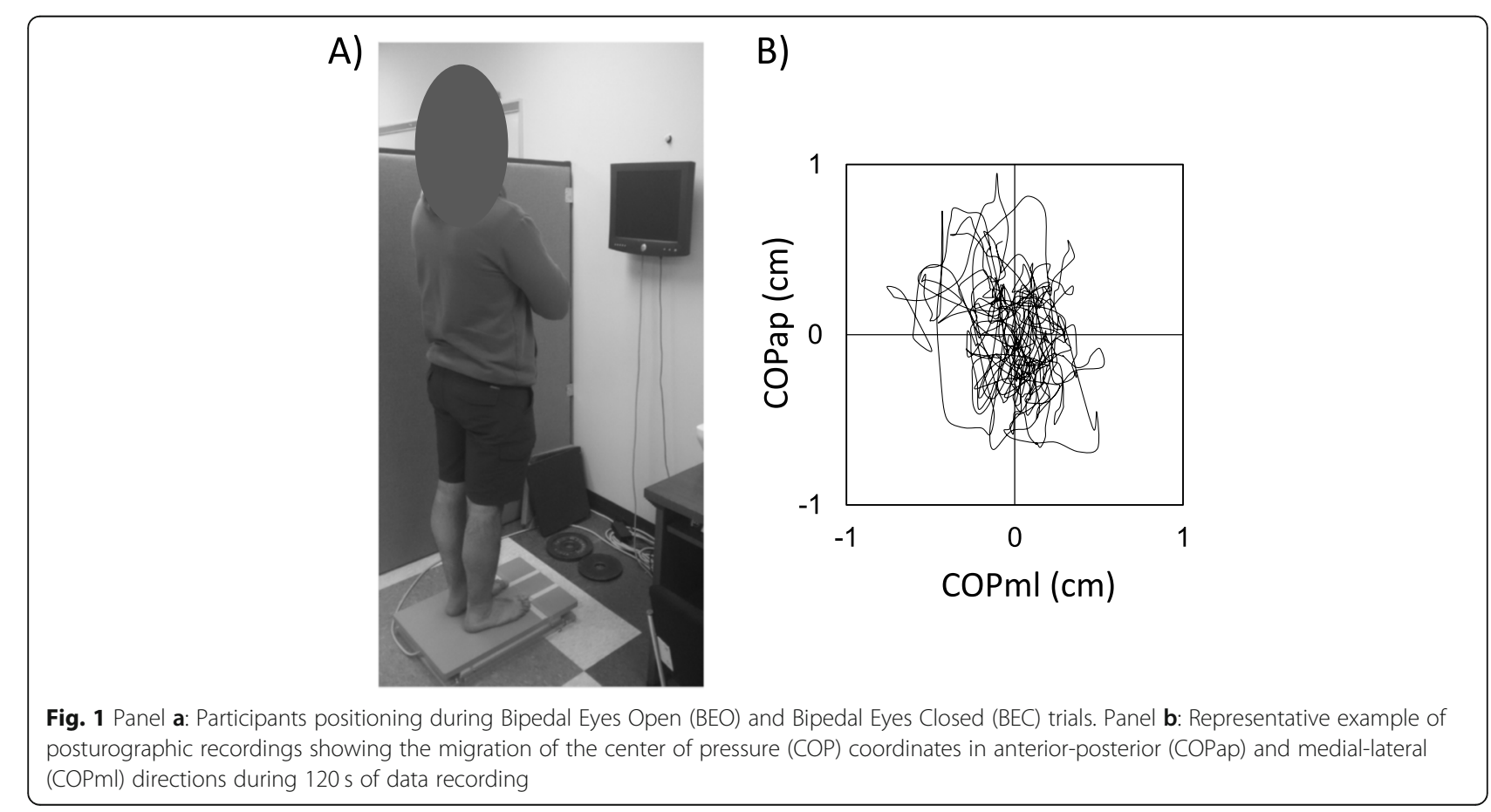


Further description of these procedures can be found in previous reports [21, 22, 27].

\section{SVV and SVH perception recording}

$S V V$ and $S V H$ perception were recorded in a representative subset of 29 female participants who were instructed to wear contoured goggles in a darkened room. They were instructed to remain seated with their head in anatomical position against a headrest (Fig. 2). A laser emitter was utilized to project a $16-\mathrm{cm}$-long monochromatic laser bar at eye level and $1.5 \mathrm{~m}$ ahead the participant. For both $S V V$ and $S V H$ tests, stimuli were designed to be offset from either the vertical or horizontal line by angular distances ranging from $5^{\circ}$ to $35^{\circ}$ in both clockwise and counterclockwise directions. Participants were provided with a response pad to adjust the laser bar position as vertical or horizontal as possible according to their perception. 12 trials for each $S V V$ and $S V H$ tests were performed in a random fashion. No time constraints for completing each trial were stipulated. The residual angle $\alpha$ was calculated between the true vertical or horizontal line and the final position of the laser bar (Fig. 2). The sensitivity of the system was $0.1^{\circ}$. Further description of these procedures can be found in a previous report [37]. Average duration of the experimental session was $20 \mathrm{~min}$ (SD $10 \mathrm{~min}$ ).

\section{Data processing}

\section{Quiet stance (VPDI) data processing}

COP coordinates from the force plate were analyzed offline with customized routines (BalanceLab vs 3.0, Synergy Applied Medical and Research Inc., USA).
A)

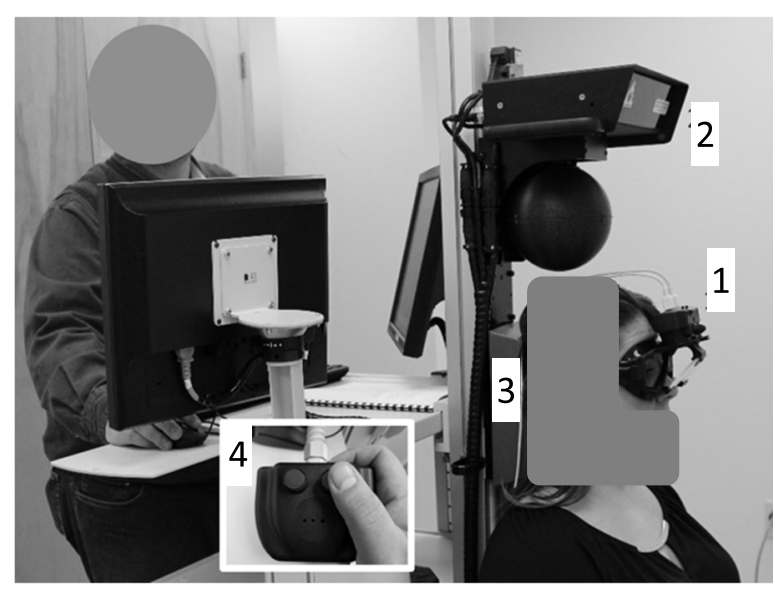

B) Subjective visual vertical (SVV)

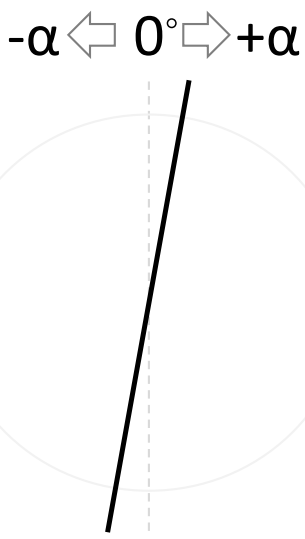

C) Subjective visual horizontal (SVH)

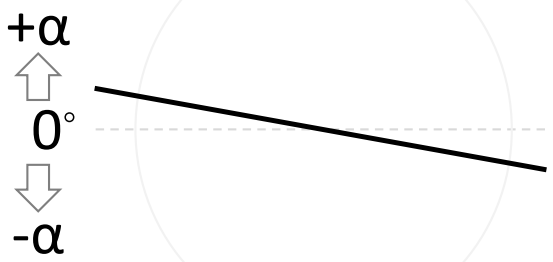

Fig. 2 Panel a: Example of positioning during subjective visual vertical and horizontal (SW and SVH, respectively) tests: (1) Eyewear utilized to restrict visual field to $110^{\circ}$, (2) Laser emitter, (3) Head rest, and (4) Remote control used for rotation of laser bar. Panels $\mathbf{b}$ and c: Schematic representation of participants' view of the laser bar (thick trace). Dashed traces and the error (a angle) are shown for illustration purposes. They were not visible to participants. Sizes and proportions have been modified for illustration purposes 
COPap and COPml coordinate signals were down sampled to $10 \mathrm{~Hz}$ and detrended by the mean of each time series. This procedure allowed to position COP coordinates at the center of an $x y$ coordinate system and draw any comparisons of basic COP features across participants. The following postural indices were computed: area of COP (COP_area), length of COP displacement (COP_total_length), maximum amplitude of COP displacement in each direction (COP_range_ap and $C O P_{-}$ range_ $m l)$, root mean square estimations of COP signals (COP_rms_ap and COP_rms_ml), mean velocities of COP displacement (COP_total_mean_vel, COP_mean $v e l \_a p$, and $\left.C O P \_m e a n \_v e l \_m l\right)$, mean jerkiness of COP displacement (COP_total_mean_jerk, COP_mean_jerk $a p$, and COP_mean_jerk_ml), median frequency of COP displacement (COP_median_freq_ap and COP_median_ freq_$m l$ ), amount of regularity and predictability of $\mathrm{COP}$ displacement in time quantified by sample entropy of COP signals (COP_sent_ap and COP_sent_ml), and degree of asynchrony or dissimilarity between COPap and $\mathrm{COPml}$ signals in time quantified by cross sample entropy (COP_crosssent).

COP_area was defined similarly to procedures employing the sector formula of Leibniz previously described and used in the literature [21, 22, 37]. COP_total_length was computed as the total length of the COP displacement during the whole stance trial. The maximum amplitudes of the COP displacement in each direction (COP_range_ap and COP_range_ml) were computed by the difference between their maximum and minimum coordinates recorded. $C O P_{-}$ total_mean_vel, COP_mean_vel_ap, and COP_mean_ $v e l \_m l$ were computed as the length of the COP trajectory divided by the duration of the trial. $C O P_{-}$ total_mean_jerk, COP_mean_jerk_ap, and COP_mean jerk $m l$ represented the time rate of COP acceleration. They were computed as the third derivative of the COP position with respect to time. COP_median freq_ap and COP_median_freq_ml were computed as the median frequency of the COP spectral power in each direction. COP_sent_ap and COP_sent_ml were computed through estimations of the correlation, persistence, and regularity of the COP signal in time. Smaller sample entropy estimates indicate many repetitive patterns of COP fluctuation in time, whereas larger estimates indicate a more irregular, random, and unpredictable pattern. COP_crosssent was computed as an estimative of the correlation, persistence, and regularity in time between the COP signal in the anterior-posterior and medial-lateral directions. Higher estimates indicate larger levels of asynchrony of postural sway between the two directions, whereas lower estimates indicate more co-dependence [21, 22, 38]. Each postural index obtained during BEO and
BEC were pair-wise subtracted and normalized as follows:

$$
\operatorname{VPDI}(\%)=[(B E C-B E O) / B E O]^{*} 100
$$

Under this approach, a VPDI represents the normalized effect of vision on one variable of interest. This value can be either zero, positive, or negative. Zero values are interpreted as a null effect of vision to postural sway behavior. Positive and negative values are interpreted as either positive (beneficial) or negative (detrimental) effects of vision to postural control, respectively.

\section{SVV and SVH perception data processing}

Regarding static $S V V$ and $S V H$ tests, across-trials averages of the error in degrees (residual angle $\alpha$ ) from each test were computed for each participant. The absolute residual angle $\alpha(S V V \alpha$ and $S V H \alpha)$ was calculated as a dependent variable, representing the $S V V$ or $S V H$ perception error.

\section{Statistical approach}

Mann-Whitney $\mathrm{U}$ tests were run to test the gender effect into all VPDIs. Due to the lack of a gender effect (Table 1), all data recorded from males and females were combined into a single sample set. Medians and quartiles for each VPDI are presented. One-sample Wilcoxon tests were employed to test the null hypothesis: VPDI equal zero (no Vision effect). Pearson correlation tests were applied to quantify the linear correlation level between participants' age (Age) and each VPDI, as well as Age and $S V V \alpha$ or $S V H \alpha$. A Pearson correlation test was also used to establish the linear correlation level between residual angles from subjective visual tests $S V V \alpha$ or $S V H \alpha$ and each VPDI. Statistical tests were performed using the IBM SPSS statistics software suite (version 22, $\mathrm{IBM}^{\circ} \mathrm{SPSS}^{\circ}$ ). A significance level of $p<0.05$ was established and a Bonferroni's pair-wise correction was applied to account for multiple comparisons.

\section{Results}

\section{Quiet stance (VPDI) results}

Table 1 shows the VPDI median and quartiles (25th and 75th) obtained across participants. These variables are ranked accordingly to their median magnitude. Most VPDIs revealed positive medians and the series of Wilcoxon one-sample tests showed all medians were significantly different from zero $(p \leq 0.002)$, but VPDI COP_sent_ml $(p=0.38)$ and VPDI COP_crosssent $(p=$ 0.20 ). The magnitude of significant VPDIs ranged from 8.87 to $45.87 \%$, revealing an effect of visual inputs to 15 postural indices indices (VPDI cop_median_freq_ap, 
Table 1 Median and quartiles of Visuo-Postural Dependency Index (VPDI) across participants $(n=102)$ for each postural index computed from center of pressure (COP) signals recorded during bipedal stance with eyes opened and closed. Results from Wilcoxon One-Sample test (visual input effect), Mann-Whitney U test (gender effect), and Pearson correlation test (age correlation) are presented

\begin{tabular}{|c|c|c|c|c|}
\hline & vpdi (\%) & $\begin{array}{l}\text { Visual Input Effect } \\
\text { (wilcoxon one-sample test) }\end{array}$ & $\begin{array}{l}\text { Gender Effect } \\
\text { (Mann-Whitney U test) }\end{array}$ & $\begin{array}{l}\text { Age CORRELATION } \\
\text { (Pearson test) }\end{array}$ \\
\hline & Median (Q1, Q3) & $p$-value & U, z (p-value) & $r$ (p-value) \\
\hline VPDI COP_median_freq_ap (\%) & $45.87(5.64,96.52)$ & $<0.001 *$ & $1018.0,-0.060(0.952)$ & $-0.18(0.065)$ \\
\hline VPDI COP_mean_vel_ap (\%) & $40.58(18.20,59.24)$ & $<0.001^{*}$ & $912.0,-0.855(0.393)$ & $-0.29(0.003)$ \\
\hline VPDI COP_area (\%) & $40.50(5.02,92.42)$ & $<0.001^{*}$ & $891.0,-1.012(0.311)$ & $-0.15(0.140)$ \\
\hline VPDI COP_total_mean_vel (\%) & $30.41(14.73,50.18)$ & $<0.001^{*}$ & $881.0,-1.087(0.277)$ & $-0.28(0.005)$ \\
\hline VPDI COP_range_ap (\%) & $25.38(2.66,48.28)$ & $<0.001^{*}$ & $922.0,-0.780(0.435)$ & $-0.11(0.292)$ \\
\hline VPDI COP_mean_jerk_ap (\%) & $23.70(7.33,38.29)$ & $<0.001^{*}$ & $968.5,-0.431(0.666)$ & $-0.29(0.003)$ \\
\hline VPDI COP_total_mean_jerk (\%) & $17.79(5.51,30.39)$ & $<0.001^{*}$ & $934.5,-0.686(0.493)$ & $-0.27(0.006)$ \\
\hline VPDI COP_sent_ap (\%) & $16.90(-0.08,39.68)$ & $<0.001^{*}$ & $1011.50,-0.109(0.913)$ & $-0.20(0.047)$ \\
\hline VPDI COP_rms_ap (\%) & $13.80(-3.05,37.65)$ & $<0.001^{*}$ & $938.0,-0.660(0.509)$ & $-0.07(0.497)$ \\
\hline VPDI COP_mean_vel_ml (\%) & $13.36(3.37,28.74)$ & $<0.001^{*}$ & $915.0,-0.832(0.405)$ & $-0.17(0.086)$ \\
\hline VPDI COP_range_ml (\%) & $13.32(-5.84,40.90)$ & $<0.001^{*}$ & $991.0,-0.262(0.793)$ & $-0.14(0.170)$ \\
\hline VPDI COP_rms_ml (\%) & $11.99(-4.21,31.62)$ & $<0.001^{*}$ & $891.0,-1.012(0.311)$ & $-0.15(0.145)$ \\
\hline VPDI COP_total_length (\%) & $11.44(-1.6,32.22)$ & $<0.001^{*}$ & $907.0,-0.889(0.372)$ & $-0.10(0.324)$ \\
\hline VPDI COP_median_freq_ml (\%) & $10.19(-17.82,41.46)$ & $0.002^{*}$ & $961.0,-0.487(0.626)$ & $-0.08(0.421)$ \\
\hline VPDI COP_mean_jerk_ml (\%) & $8.87(0.91,17.60)$ & $<0.001^{*}$ & $906.0,-0.900(0.368)$ & $-0.17(0.096)$ \\
\hline VPDI COP_sent_ml (\%) & $0.99(-10.15,16.30)$ & 0.384 & $1012.00,-0.105(0.916)$ & $-0.01(0.954)$ \\
\hline VPDI COP_crosssent (\%) & $-2.96(-21.09,13.02)$ & 0.206 & $989.00,-0.277(0.781)$ & $0.07(0.468)$ \\
\hline
\end{tabular}

$* p<0.0029$

VPDI cop_mean_vel_ap, VPDI cop_area, VPDI cop_ total_mean_vel, VPDI cop_range_ap, VPDI cop_mean_ jerk_ap, VPDI cop_total_mean_jerk, VPDI cop_sent_ap, VPDI cop_rms_ap, VPDI cop_mean_vel_ml, VPDI cop_ range_ml, VPDI cop_rms_ml, VPDI cop_total_length, VPDI cop_median_freq_ml, VPDI cop_mean_jerk_ml). A series of Mann-Whitney $U$ tests did not show any significant effect of Gender (male vs female) on any of the VPDIs (Table 1). In addition, a Bonferroni's correction was applied and no significant correlations were found between VPDIs and Age (Table 1).

\section{SVV and SVH perception results}

Table 2 presents correlation results between either $S V V \alpha$ or $S V H \alpha$ and each VPDI computed for two age groups: young adults (16-30 years old) and older adults (50-74 years old). These age subgroups were selected to provide a significant distance in between the ages of the groups as well as include the early changes in postural control found in the fifth decade of life [39]. After application of Bonferroni's correction, no significant correlations were found between $S V V \alpha$ or $S V H \alpha$ and any VPDI.

\section{Discussion}

Quiet stance VPDIs and their sensitivity to visual inputs

The results uncovered here confirmed our primary hypothesis: $94.4 \%$ of VPDIs investigated were sensitive to the full modulation of visual inputs. This result provides evidence that multiple indices representing more than one domain of COP signal analysis should be used to assess visual dependency to postural control. Specifically, all indices investigated in the temporal, spatial, and frequency domains, and one index in the structural domain (VPDI COP_sent_ap) were statistically robust to quantify the impact of visual inputs to the postural sway dynamics. This finding aligns with other investigations [40-42]. For example, Sim et al. (2018) applied a discrete wavelet transform to study the energy content of the COPap signal within frequency bands below and above $1 \mathrm{~Hz}$. They have reported a temporary interruption of visual inputs can cause significant shifts in the spectral energy signal content in bands up to $1 \mathrm{~Hz}$. Specific changes included reductions of energy content below $0.1 \mathrm{~Hz}$ and increases on frequency bands up to $1 \mathrm{~Hz}$. These findings become relevant considering that the lower frequency content embedded in the COP signals has been linked to the visual neural loops involved in postural control [43-46]. 
Table 2 Pearson correlation ( $r$ ) obtained between each Visuo-Postural Dependency Indices (VPDI) and the absolute residual angle from either subjective visual vertical or horizontal test (SWa and SVHa, respectively). Note: adjusted p-value considered for inferential statistics is 0.0029

\begin{tabular}{|c|c|c|c|c|}
\hline & \multicolumn{4}{|c|}{ Pearson $r$ ( $p$-value) } \\
\hline & \multicolumn{2}{|c|}{ Young Adults $(n=13)$} & \multicolumn{2}{|c|}{ Older Adults $(n=16)$} \\
\hline & $S V V a$ & SVHa & $S V V a$ & SVHa \\
\hline VPDI COP_median_freq_ap (\%) & $0.12(0.714)$ & $-0.07(0.833)$ & $0.07(0.797)$ & $0.08(0.773)$ \\
\hline VPDI COP_mean_vel_ap (\%) & $0.75(0.005)$ & $0.05(0.869)$ & $-0.18(0.497)$ & $-0.16(0.563)$ \\
\hline VPDI COP_area (\%) & $0.54(0.069)$ & $0.08(0.810)$ & $-0.30(0.258)$ & $-0.06(0.818)$ \\
\hline VPDI COP_total_mean_vel (\%) & $-0.09(0.774)$ & $-0.22(0.500)$ & $0.26(0.329)$ & $0.27(0.317)$ \\
\hline VPDICOP_range_ap (\%) & $0.76(0.004)$ & $0.05(0.877)$ & $-0.28(0.293)$ & $-0.22(0.423)$ \\
\hline VPDI COP_mean_jerk_ap (\%) & $0.02(0.943)$ & $-0.01(0.965)$ & $0.37(0.162)$ & $0.32(0.224)$ \\
\hline VPDI COP_total_mean_jerk (\%) & $-0.20(0.526)$ & $-0.08(0.808)$ & $0.25(0.354)$ & $0.35(0.185)$ \\
\hline VPDI COP_sent_ap (\%) & $-0.21(0.522)$ & $-0.05(0.888)$ & $0.03(0.920)$ & $0.20(0.453)$ \\
\hline VPDI COP_rms_ap (\%) & $-0.12(0.721)$ & $-0.20(0.525)$ & $0.65(0.007)$ & $0.44(0.087)$ \\
\hline VPDI COP_mean_vel_ml (\%) & $-0.41(0.184)$ & $-0.40(0.201)$ & $-0.09(0.745)$ & $-0.19(0.484)$ \\
\hline VPDI COP_range_ml (\%) & $-0.42(0.169)$ & $-0.37(0.241)$ & $-0.17(0.523)$ & $-0.20(0.452)$ \\
\hline VPDI COP_rms_ml (\%) & $-0.20(0.527)$ & $-0.40(0.202)$ & $0.13(0.630)$ & $-0.12(0.661)$ \\
\hline VPDI COP_total_length (\%) & $-0.68(0.015)$ & $-0.04(0.908)$ & $0.23(0.395)$ & $0.18(0.509)$ \\
\hline VPDI COP_median_freq_ml (\%) & $-0.17(0.597)$ & $-0.22(0.488)$ & $0.11(0.678)$ & $0.02(0.947)$ \\
\hline VPDI COP_mean_jerk_ml (\%) & $-0.76(0.004)$ & $-0.20(0.542)$ & $0.32(0.224)$ & $0.24(0.366)$ \\
\hline VPDI COP_sent_ml (\%) & $-0.19(0.545)$ & $-0.16(0.619)$ & $-0.09(0.742)$ & $-0.25(0.341)$ \\
\hline VPDI COP_crosssent (\%) & $-0.35(0.264)$ & $-0.30(0.337)$ & $0.17(0.532)$ & $-0.07(0.793)$ \\
\hline
\end{tabular}

The relation of specific modalities of sensory information to the energy content of the COP signal has been an area of interest in human motor control. Studies of this nature are based on the effects of neural networks complexity to the time for completion of recurring neural loops. Under this principle, more complex sensory systems (composed by longer circuits) require longer delays reaching their targeted structures. As a result, there is an addition of lower frequencies components to the COP signal. Based on previous experimentation, visual inputs are credited to add energy content to frequencies below $0.1 \mathrm{~Hz}$, while vestibular and somatosensory inputs are linked to frequency bands of $0.1-0.5 \mathrm{~Hz}$ and $0.5-1.0 \mathrm{~Hz}$, respectively $[43,44,46]$. Our results corroborate this idea. We found positive VPDI for the median frequency of the COP displacement in both anteriorposterior and medial-lateral directions. It was an indicative of energy increase occurring towards larger frequencies when both vestibular and somatosensory neural relays become the main sources of sensory inputs. In addition, it reinforces the robustness of the VPDIs on capturing subtle changes in body balance behavior due to visual input modulation.

$V P D I$ s from the spatial and temporal domains (area, sway amplitude, root mean square, mean velocities, and signal jerk) were also found to be indicators of full visual modulation. Vision interruption caused participants to significantly increase their sway area, amplitude, and mean velocities. These increases were consistently more expressive in the anterior-posterior, when compared to the medial-lateral direction. These findings align with other reports showing similar effects [24, 25, 47-50]. Taken together, these studies and ours support the rationale that vision is the sensory modality producing the most reliable source of information for postural control [51-53]. Under this rationale, visual inputs are constantly fed into the CNS resulting in the construction of an internal representation of one's relation to its surroundings (exteroception). This information is integrated to other inputs to elaborate a motor response. Finally, motor outputs are sent to postural muscles responsible for stabilization of major joints along the axial skeleton (e.g. ankle, knee, hip, and intervertebral joints). However, once vision is disrupted, the quality of exteroception information is reduced, and production of motor outputs is performed under reduced levels of certainty regarding the body's current state and dynamics. As a result, the vertical position becomes less stable and body sway is performed with larger amplitudes and faster speeds. This observation is particularly supported by studies reporting the strong influence that motion of the visual field has on inducing phase-locked body sway motion [54-57]. The impact of low illumination on postural control has also shown significant increases in postural 
sway in both young and elderly participants, although this increase is significantly smaller than those observed in the eyes closed or complete darkness condition [58].

Regarding COP signal's jerk, we observed a significant positive modulation of VPDIs representing COP jerk levels. This quantity is considered as an empirical measure of smoothness of posture sway and a measure of one's ability to control motion acceleration [59]. We interpreted $\mathrm{COP}$ jerkiness as a sign for the presence of movement corrections executed in real time that emerges when sensory-motor integration becomes suboptimal. Partial support for this rationale originates from previous studies showing higher levels of jerk on COP signals recorded from patients suffering from Parkinson's and Huntington's disease [59, 60]. Despite its unclear mechanisms, such corrections are likely driven by bursts of muscular contractions aiming to decelerate the body when sway speed is elevated. Once employed, these bursts can cause short-time deviations of the COP signals from its expected pathway, and increase its degree of randomness. In fact, our results also revealed a significant positive modulation of the VPDI representing COPap signal's sample entropy signaling increase on its randomness. At this time, such interpretations are only speculative and need to be investigated by dedicated experimentation.

Vision did not affect the co-dependence between COPap and COPml in healthy persons. COP_crosssent estimates revealed no significative changes in the synchronization between the anterior-posterior and medial-lateral $C O P$ displacement. Standing upright on boards with reduced support areas have affected how postural sway in both directions behave. Smaller support area (i.e. more unstable base of support) led to increased postural sway. However, a decrease in the larger dimension of the support area led to an increase in body sway above and beyond the effects of changing the smaller dimension [61]. This study suggested that anteriorposterior and medial-lateral postural sway might be more associated during unstable conditions. According to our results, it is suggested that visual-postural dependency and mechanical-postural dependency might not induce changes in the association between postural sway directions.

The degree of modulation across significant VPDIs was found to be remarkedly variable. VPDIs representing COPap characteristics revealed larger modulations compared with COPml. Based on this observation, it becomes tempting to speculate about the potential sensitivity of these measures in populations suffering from neuromuscular disorders. However, several cohorts of patients suffering from these disorders need to be studied so a conclusion could be reached. At this time, we can only expect these variations in modulation will allow the uncovering of independent patterns of visual dependency behaviors across the neuromuscular disease spectrum.

\section{Quiet stance VPDIs and aging}

According to the literature, conventional postural indices are sensitive to age. Several investigations show older individuals progress along their late stages of life with larger, faster, more variable, and more irregular body sway in time, compared to young adults when performing bipedal stance with eyes opened [25, 47, 50, 62-64]. These changes are usually associated with the natural process of aging and its declines in sensorial, neural, and motor functioning [50, 65-68].

The use of VPDIs allowed us to take a step forward and assess the functional integrity of sensory-motor integration of visual inputs, while reducing the age-related effects of other sensory modalities. Under this approach, our results showed a general lack of strong relationships between age and each VPDI. This observation is dissonant to studies showing a decreased reliance on visual inputs to control balance after age of 65 years [69]. We believe this difference in results is related to the multivariate approach taken for our analyzes. The application of a Bonferroni's correction to multiple comparisons reduced seventeen-fold the threshold for inferential decision. Such approach reduced our ability to capture weaker but significant effects happening to a few variables of interest. When these variables are studied independently, a negative relationship emerged between age and VPDI for COP velocity, jerk, and sample entropy. These correlations were found mainly on the anteriorposterior direction, suggesting that the effect of visual input on medial-lateral body sway was not dependent on the age.

It has been reported that decreases in visual reliance is due to the deterioration visual's peripherical and central organs [70]. However, the age-related deteriorations affect all organic human systems. Therefore, the deterioration of the vestibular and proprioceptive systems are also expected, such as reduced visual acuity and accommodation, contour and depth perception, contrast sensitivity, peripheral vision, pupil size and agility, kinesthetic sensitivity, joint position sense at the ankle, and cutaneous sensation are reported in the literature [50, 71, 72]. Based on this rationale, one can speculate that aging of all sensory systems may occur at different rates and result in favoring CNS' reliance on those systems with lower rates of deterioration or lower complexity. Currently, it is unclear the rate of progression and how this reorganization is implemented. However, this idea is supported by compounding evidence emerging from neuroimaging studies showing that the age-related effects across sensory systems differ [73, 74]. For example, 
deterioration of vestibular substrate has been welldocumented to be linked to volume reduction of vestibular nuclei in the brainstem and reduction of cerebellar volume [73]. On the other hand, evidence of age-related changes in the visual cortex is primarily associated with functional aspects of neurons and neuronal communication in the visual system [70]. Such differences may induce loss of function at different degrees and rates and a constant necessity for the CNS to adapt its processing of sensory-motor integration during the aging years. It is possible that some may respond more efficiently to such re-organizations, while others may develop deficits resulting in higher risks or prevalence of falls. Such investigations are still to be developed.

Spatiotemporal variables are important indicators about how the CNS controls postural sway and avoid the COP reaching the limits of the body's base of support. When such mechanisms fail, the likelihood of a fall increases. Note that when adults closed their eyes, both COP velocity and jerk increased. In addition, this increase tended to be reduced with aging (Table 2). Such associations were observed mostly for the anteriorposterior sway. These findings may be related to the mechanical properties of the axial skeleton. For example, during the execution of an upright standing posture with parallel feet position, anterior-posterior postural sway control is mostly dependent on the ability of anterior and posterior muscle groups (lower limbs and trunk) to generate the necessary torque to avoid a fall. On the other hand, medial-lateral sway is partially counteracted by the mechanical presence of two lower limbs and joints that are inherently more restricted to movements in the frontal plane. Under this rationale, one can expect that age-related muscle strength loss associated with the changes in the visual sensory inputs may have a larger impact to body-sway in the anterior-posterior direction in healthy participants.

\section{Quiet stance VPIDs and their relation to SVV and SVH perception}

Vertical and horizontal perception were within normal values. This result was expected considering that the cohort was formed by healthy individuals with no sensory disorders. Bonferroni's correction was applied, and no significant correlations were found between VPDIs and either $S V H$ or $S V V$, for both young and older groups. Such results corroborated our idea of including VPDIs to improve current methods of visual dependency investigation. Despite the fact posturography and SVV/SVH procedures examine one's visual dependency, they are distinct tasks representing different mechanical and cognitive constraints. For example, during the execution of $S V V$ and $S V H$ tasks, participants remain seated. Emphasis is shared between the mechanical maintenance of head orientation and the attention directed to a primary visual task of correcting the laser bar. On the other hand, the focus during quiet stance is on the mechanical maintenance of several body segments (trunk and lower extremities), and there is no primary visual task. Based on this rationale, one can expect these two tasks to elicit distinct neuromechanisms resulting in a few to none correlated indicators. Therefore, we interpret our findings as a step forward to understand visual dependency.

\section{Conclusions}

The utilization of quiet stance visuo-postural dependency indices (VPDIs) showed to be a robust method to investigate visual input dependency to one's postural control. Due to its multidimensional nature, this approach allows the assembly of a larger comprehensive panel of body sway characteristics. Our findings can be further examined by scientists and clinicians aiming to uncover subtle modification to the process of visual inputs integration in bipedal stance control.

\section{Abbreviations}

CNS: Central nervous system; SW: Subjective visual vertical; SVH: Subjective visual horizontal; COP: Center of pressure; VPDI: Visuo-postural dependency index; GRF: Ground reaction force; BEO: bipedal eyes open; BEC: bipedal eyes closed; COPap: center of pressure in anterior-posterior direction;

COPml: center of pressure in medial-lateral direction; COP_area: center of pressure total area of sway; COP_total_length: center of pressure total length of sway; COP_range_ap: center of pressure signal maximum amplitude in anterior-posterior direction; COP_range_ml: center of pressure signal

maximum amplitude in medial-lateral direction; COP_rms_ap: root mean square of center of pressure signal in anterior-posterior direction;

COP_rms_ml: root mean square of center of pressure signal in medial-lateral direction; COP_total_mean_vel: center of pressure mean velocity;

COP_mean_vel_ap: center of pressure mean velocity in anterior-posterior direction; COP_mean_vel_ml: center of pressure mean velocity in medial-lateral direction; COP_total_mean_jerk: mean jerk of center of pressure signal; COP_mean_jerk_ap: mean jerk of center of pressure anterior-posterior's signal; COP_mean_jerk_ml: mean jerk of center of pressure medial-lateral's signal; COP_median_freq_ap: median frequency of signal representing the center of pressure in anterior-posterior direction;

COP_median_freq_ml: median frequency of signal representing the center of pressure in medial-lateral direction; COP_sent_ap: sample entropy of signal representing the center of pressure in anterior-posterior direction; COP_sent_ml: sample entropy of signal representing the center of pressure in medial-lateral direction; COP_crosssent: cross entropy of center of pressure signal

\section{Acknowledgements}

Not applicable.

\section{Authors' contributions \\ ADS formulated concepts and design of the study, analysis and interpretation of the data and writing of the manuscript. AMD, PD, and $L M$ contributed to the writing of the manuscript. ADS, AMD, MMRS, VSC, and ATM contributed with data recording and analyzes. All authors read and approved the manuscript and have given consent for the submission of the final article.}

Funding

No funding was received for this project.

Availability of data and materials

The datasets used and/or analyzed during the current study are available from the corresponding author on reasonable request. 


\section{Ethics approval and consent to participate}

This study was performed in accordance with the Declaration of Helsinki and approved by the Institutional Review Board of the University of Montana (Missoula, MT. USA). Procedures, associated risks, and potential benefits of participation were explained to each participant and written informed consent was obtained prior to commencement of the study.

\section{Consent for publication}

Not applicable.

\section{Competing interests}

The authors declare that they have no competing interests.

\section{Author details}

'Laboratory for Advances in Rehabilitation Sciences, Department of Physical Therapy, Western Michigan University, 1903 W Michigan Av., Office \# 3454, Kalamazoo, Ml 49008-5383, USA. ${ }^{2}$ Brunel University, West London, UK. ${ }^{3}$ BioSignal Laboratory, School of Physical Therapy, Federal University of Piaú, Parnaíba, PI, Brazil. ${ }^{4}$ Physical Therapy Department, Federal University of São Carlos, São Carlos, SP, Brazil. ${ }^{5}$ School of Arts, Sciences and Humanities, University of São Paulo, São Paulo, SP, Brazil.

\section{Received: 21 October 2020 Accepted: 17 January 2021}

Published online: 26 January 2021

\section{References}

1. Peterka RJ. Sensorimotor integration in human postural control. J Neurophysiol. 2002;88(3):1097-118.

2. Mergner T, Maurer C, Peterka RJ. A multisensory posture control model of human upright stance. In: Progress in Brain Research. 2003.

3. Ajrezo L, Wiener-Vacher S, Bucci MP. Saccades improve postural control: A developmental study in normal children. PLoS One. 2013;8(11):e81066

4. Legrand A, Mazars KD, Lazzareschi J, Lemoine C, Olivier I, Barra J, et al. Differing effects of prosaccades and antisaccades on postural stability. Exp Brain Res. 2013:227(3):397-405.

5. Muelas Pérez R, Sabido Solana R, Barbado Murillo D, Moreno Hernández FJ. Visual availability, balance performance and movement complexity in dancers. Gait Posture. 2014;40(4):556-60.

6. Witkin HA, Asch SE. Studies in space orientation. IV. Further experiments on perception of the upright with displaced visual fields. J Exp Psychol. 1948; 38(6):762-82.

7. Chang YT, Meng LF, Chang CJ, Lai PL, Lung CW, Chern JS. Effect of postural control demands on early visual evoked potentials during a subjective visual vertical perception task in adolescents with idiopathic scoliosis. Front Hum Neurosci. 2017;11:326.

8. Chang TP, Winnick AA, Hsu YC, Sung PY, Schubert MC. The bucket test differentiates patients with MRI confirmed brainstem/cerebellar lesions from patients having migraine and dizziness alone. BMC Neurol. 2019;19(1):219.

9. Naik C. Investigating a patient of vertigo: where do we stand today? Indian journal of otology; 2017.

10. Halmagyi GM, Gresty MA, Gibson WPR. Ocular tilt reaction with peripheral vestibular lesion. Ann Neurol. 1979;6(1):80-3.

11. Tabak S, Collewijn H, Boumans LJJM. Deviation of the subjective vertical in long-standing unilateral vestibular loss. Acta Otolaryngol. 1997;117(1):1-6.

12. Friedmann $\mathrm{G}$. The influence of unilateral labyrinthectomy on orientation in space. Acta Otolaryngol. 1971;71(4):289-98.

13. Min KK, Ha JS, Kim MJ, Cho CH, Cha HE, Lee JH. Clinical use of subjective visual horizontal and vertical in patients of unilateral vestibular neuritis. Otol Neurotol. 2007;28(4):520-5.

14. Guerraz M, Yardley L, Bertholon P, Pollak L, Rudge P, Gresty MA, et al. Visual vertigo: symptom assessment, spatial orientation and postural control. Brain. 2001;124(Pt 8):1646-56.

15. Ushio M, Murofushi T, Iwasaki S. Subjective visual horizontal in patients with posterior canal benign paroxysmal positional vertigo. Acta Otolaryngol. 2007:127(8):836-8.

16. Agarwal K, Bronstein AM, Faldon ME, Mandalà M, Murray K, Silove Y. Visual dependence and BPPV. J Neurol. 2012;259(6):1117-24.

17. Cousins S, Cutfield NJ, Kaski D, Palla A, Seemungal BM, Golding JF, et al. Visual dependency and dizziness after vestibular neuritis. PLoS One. 2014; 9(9):e105426.

18. Ivanenko Y, Gurfinkel VS. Human postural control. Front Neurosci. 2018.
19. Danna-dos-Santos A, Degani AM, Latash ML. Flexible muscle modes and synergies in challenging whole-body tasks. Exp Brain Res. 2008;189(2):171-8.

20. Danna-Dos-Santos A, Shapkova EY, Shapkova AL, Degani AM, Latash ML. Postural control during upper body locomotor-like movements: similar synergies based on dissimilar muscle modes. Exp Brain Res. 2009;193(4): 565-79.

21. Degani AM, Leonard CT, Danna-dos-Santos A. The effects of early stages of aging on postural sway: a multiple domain balance assessment using a force platform. J Biomech. 2017;64:8-15.

22. Degani AM, Santos MM, Leonard CT, Rau TF, Patel SA, Mohapatra S, et al. The effects of mild traumatic brain injury on postural control. Brain Inj. 2017; 31(1):49-56.

23. Simoneau GG, Leibowitz HW, Ulbrecht JS, Tyrrell RA, Cavanagh PR. The effects of visual factors and head orientation on postural steadiness in women 55 to 70 years of age. Journals Gerontol. 1992;47(5):M151-8.

24. Prieto TE, Myklebust JB, Hoffmann RG, Lovett EG, Myklebust BM. Measures of postural steadiness: differences between healthy young and elderly adults. IEEE Trans Biomed Eng. 1996;43(9):956-66.

25. Benjuya N, Melzer I, Kaplanski J. Aging-induced shifts from a reliance on sensory input to muscle Cocontraction during balanced standing. Journals Gerontol - Ser A Biol Sci Med Sci. 2004.

26. Hansson EE, Beckman A, Håkansson A. Effect of vision, proprioception, and the position of the vestibular organ on postural sway. Acta Otolaryngol. 2010;59(2):166-71.

27. Danna-Dos-Santos A, Degani AM, Boonstra TW, Mochizuki L, Harney AM, Schmeckpeper MM, et al. The influence of visual information on multimuscle control during quiet stance: a spectral analysis approach. Exp Brain Res. 2014.

28. Nashner LM, Peters JF. Dynamic posturography in the diagnosis and management of dizziness and balance disorders. Neurologic Clinics. 1990; 8(2):331-49

29. Ford-Smith CD, Wyman JF, Elswick RK, Fernandez T, Newton RA. Test-retest reliability of the sensory organization test in noninstitutionalized older adults. Arch Phys Med Rehabil. 1995;76(1):77-81.

30. Ozkul C, Guclu-Gunduz A, Eldemir K, Apaydin Y, Gulsen C, Yazici G, et al. Effect of task-oriented circuit training on motor and cognitive performance in patients with multiple sclerosis: a single-blinded randomized controlled trial. NeuroRehabilitation. 2020;46(3):343-53.

31. Tesio L, Longo S, Rota $V$. The subjective visual vertical: validation of a simple test. Int J Rehabil Res. 2011;34(4):307-15.

32. Dieterich $M$, Brandt T. Ocular torsion and tilt of subjective visual vertical are sensitive brainstem signs. Ann Neurol. 1993;33(3):292-9.

33. Böhmer A, Rickenmann J. The subjective visual vertical as a clinical parameter of vestibular function in peripheral vestibular diseases. J Vestib Res. 1995;5(1):35-45.

34. Tribukait A, Bergenius J, Brantberg K. Subjective visual horizontal during follow-up after unilateral vestibular deafferentation with gentamicin. Acta Otolaryngol. 1998;118(4):479-87.

35. Zakaria MN, Wahat NHA, Zainun Z, Sakeri NSM, Salim R. The test-retest reliability of subjective visual horizontal testing: comparisons between solid and dotted line images. J Audiol Otol. 2020.

36. Barra J, Marquer A, Joassin R, Reymond C, Metge L, Chauvineau V, et al. Humans use internal models to construct and update a sense of verticality. Brain. 2010;

37. Almutairi A, Cochrane GD, Christy JB. Vestibular and oculomotor function in children with CP: descriptive study. Int J Pediatr Otorhinolaryngol [internet]. 2019;119(November 2018):15-21. Available from: https://doi.org/https://doi. org/10.1016/j.ijporl.2018.12.038.

38. Richman JS, Moorman JR. Physiological time-series analysis using approximate and sample entropy. Am J Physiol Heart Circ Physiol. 2000.

39. Schumacher J, Pientka L, Trampisch U, Moschny A, Hinrichs T, Thiem U. The prevalence of falls in adults aged 40 years or older in an urban. German population Z Gerontol Geriatr. 2014.

40. Sim T, Yoo H, Lee D, Suh SW, Yang JH, Kim H, et al. Analysis of sensory system aspects of postural stability during quiet standing in adolescent idiopathic scoliosis patients. J Neuroeng Rehabil. 2018;

41. Singer JC, Mochizuki G. Post-stroke lower limb spasticity alters the interlimb temporal synchronization of centre of pressure displacements across multiple timescales. IEEE Trans Neural Syst Rehabil Eng. 2015;

42. Taguchi K. Spectral analysis of the movement of the center of gravity in vertiginous and ataxic patients. Agressologie. 1978. 
43. Baratto L, Morasso PG, Re C, Spada G. A new look at posturographic analysis in the clinical context: sway-density vs. other parameterization techniques. Mot Control. 2002;6:246-70.

44. Taguchi K. Spectral analysis of the movement of the center of gravity in vertiginous and ataxic patients. Agressologie. 1978;19(B):69-70.

45. Gilfriche P, Deschodt-Arsac V, Blons E, Arsac LM. Frequency-specific fractal analysis of postural control accounts for control strategies. Front Physiol. 2018;9(MAR):1-15.

46. Golomer E, Dupui P, Bessou P. Spectral frequency analysis of dynamic balance in healthy and injured athletes. Arch Physiol Biochem. 1994; 102(3):225-9.

47. Seigle B, Ramdani S, Bernard PL. Dynamical structure of center of pressure fluctuations in elderly people. Gait Posture. 2009;

48. Vieira T De MM, Oliveira LF De, Nadal J. An overview of age-related changes in postural control during quiet standing tasks using classical and modern stabilometric descriptors. J Electromyogr Kinesiol. 2009;

49. Fino PC, Mojdehi AR, Adjerid K, Habibi M, Lockhart TE, Ross SD. Comparing Postural Stability Entropy Analyses to Differentiate Fallers and Non-fallers. Ann Biomed Eng. 2016;

50. Wiesmeier IK, Dalin D, Maurer C. Elderly use proprioception rather than visual and vestibular cues for postural motor control. Front Aging Neurosci. 2015:

51. Latash ML. Neurophysiological Basis of Movement. 2nd ed. Human Kinetics Publishers Inc.; 2008. 427 p.

52. Waller D, Hodgson E. Sensory contributions to spatial knowledge of real and virtual environments. In: Human Walking in Virtual Environments: Perception, Technology, and Applications. 2013.

53. Klein TJ, Jeka J, Kiemel T, Lewis MA. Navigating sensory conflict in dynamic environments using adaptive state estimation. Biol Cybern. 2011;

54. Mahboobin A, Loughlin PJ, Redfern MS, Sparto PJ. Sensory re-weighting in human postural control during moving-scene perturbations. Exp Brain Res. 2005 Nov; 167(2):260-7

55. Borger LL, Whitney SL, Redfern MS, Furman JM. The influence of dynamic visual environments on postural sway in the elderly. J Vestib Res Equilib Orientat. 1999;

56. Oie KS, Kiemel T, Jeka JJ. Multisensory fusion: simultaneous re-weighting of vision and touch for the control of human posture [Internet]. Vol. 14, Cognitive Brain Research. 2002. Available from: www.elsevier.com/ locate/bres

57. Polastri PF, Barela JA. Adaptive visual re-weighting in children's postural control. PLoS One. 2013;

58. Rugelj D, Gomišček $G$, Sevšek F. The influence of very low illumination on the postural sway of young and elderly adults. PLoS One. 2014;

59. Mancini M, Horak FB, Zampieri C, Carlson-Kuhta P, Nutt JG, Chiari L. Trunk accelerometry reveals postural instability in untreated Parkinson's disease. Park Relat Disord. 2011;

60. Purcell NL, Goldman JG, Ouyang B, Bernard B, O'Keefe JA. The Effects of Dual-Task Cognitive Interference and Environmental Challenges on Balance in Huntington's Disease. Mov Disord Clin Pract. 2019;

61. Mochizuki L, Duarte M, Amadio AC, Zatsiorsky VM, Latash ML. Changes in postural sway and its fractions in conditions of postural instability. J Appl Biomech. 2006;

62. Amiridis IG, Hatzitaki $V$, Arabatzi F. Age-induced modifications of static postural control in humans. Neurosci Lett. 2003;

63. Demura SI, Kitabayashi T, Aoki H. Body-sway characteristics during a static upright posture in the elderly. Geriatr Gerontol Int. 2008;

64. Borg FG, Laxaback G. Entropy of balance - some recent results. J Neuroeng Rehabil. 2010.

65. Doherty TJ, Vandervoort AA, Brown WF. Effects of ageing on the motor unit: a brief review. Canadian journal of applied physiology = Revue canadienne de physiologie appliquée. 1993.

66. Good CD, Johnsrude IS, Ashburner J, Henson RNA, Friston KJ, Frackowiak RSJ. A voxel-based morphometric study of ageing in 465 normal adult human brains. Neuroimage. 2001.

67. Horak FB, Shupert CL, Mirka A. Components of postural dyscontrol in the elderly: a review. Neurobiol Aging. 1989.

68. Papegaaij S, Taube W, Baudry S, Otten E, Hortobágyi T. Aging causes a reorganization of cortical and spinal control of posture. Front Aging Neurosci. 2014.

69. Lord SR, Ward JA. Age-associated differences in sensori-motor function and balance in community dwelling women. Age Ageing. 1994;
70. Andersen GJ. Aging and vision: changes in function and performance from optics to perception. Wiley Interdiscip Rev Cogn Sci. 2012

71. Kelly JS. Visual impairment among older people. [Internet]. Vol. 2, British journal of nursing (Mark Allen Publishing). Br J Nurs; 1993 [cited 2020 Oct 5]. p. 110-6. Available from: https://pubmed.ncbi.nlm.nih.gov/8448423/

72. Lewis C. Aging: the health care challenge. 4th ed. F.A. Davis Company; 2002. 394 p.

73. Jacob A, Tward DJ, Resnick S, Smith PF, Lopez C, Rebello E, et al. Vestibular function and cortical and sub-cortical alterations in an aging population. Heliyon. 2020;

74. Arshad Q, Seemungal BM. Age-related vestibular loss: current understanding and future research directions. Front Neurol. 2016.

\section{Publisher's Note}

Springer Nature remains neutral with regard to jurisdictional claims in published maps and institutional affiliations.
Ready to submit your research? Choose BMC and benefit from:

- fast, convenient online submission

- thorough peer review by experienced researchers in your field

- rapid publication on acceptance

- support for research data, including large and complex data types

- gold Open Access which fosters wider collaboration and increased citations

- maximum visibility for your research: over $100 \mathrm{M}$ website views per year

At $\mathrm{BMC}$, research is always in progress.

Learn more biomedcentral.com/submissions 